\title{
Treatment of postoperative atrial fibrillation: The long road ahead
}

\author{
Dawn S. Hui, MD, ${ }^{\mathrm{a}}$ and Richard Lee, MD, $\mathrm{MBA}^{\mathrm{b}}$
}

\footnotetext{
From the ${ }^{a}$ Department of Cardiothoracic Surgery, University of Texas Health Science Center at San Antonio, San Antonio, Tex; and ${ }^{\mathrm{b}}$ Division of Cardiothoracic Surgery, Department of Surgery, Medical College of Georgia, Augusta University, Augusta, Ga.

Received for publication April 5, 2019; revisions received May 14, 2019; accepted for publication May 16, 2019; available ahead of print July 26, 2019

Address for reprints: Richard Lee, MD, MBA, Department of Surgery, Medical College of Georgia, 1120 15th St, BA-4300, Augusta, GA 30912 (E-mail: ricklee@ augusta.edu).

J Thorac Cardiovasc Surg 2020;159:1840-3

$0022-5223 / \$ 36.00$

Copyright (c) 2019 Published by Elsevier Inc. on behalf of The American Association for Thoracic Surgery https://doi.org/10.1016/j.jtcvs.2019.05.066
}

During the past few decades, there have been numerous advances in the surgical treatment of atrial fibrillation (AF), with well-established, evidence-based recommendations. ${ }^{1}$ Contrast this with the treatment of postoperative $\mathrm{AF}$ (POAF) following cardiac surgery: The 2014 American Heart Association/American College of Cardiology/Heart Rhythm Society guideline, ${ }^{2}$ which included input from a on POAF for cardiac and thoracic surgery: beta-blockade and calcium channel blockers are Class I recommendations, whereas prophylactic amiodarone, ibutilide, or direct current cardioversion; maintenance with antiarrhythmic medications; antithrombotic medications; and rate control/ anticoagulation/cardioversion are all Class II recommendations described as reasonable therapies. These did not markedly differ from the 2006 guidelines. Regarding patients undergoing cardiac surgery, the recently published 2019 guideline update, ${ }^{3}$ endorsed by the Society of Thoracic Surgeons (STS), adds only that apixaban and edoxaban may be equitable alternatives to warfarin in patients with $\mathrm{AF}$ and remote bioprosthetic valve implantations, and that further study is needed before recommending use of the Congestive heart failure, Hypertension, Age, Diabetes, and Stroke/ Transient Ischemic Attack Vascular Disease $\left(\mathrm{CHA}_{2} \mathrm{DS}_{2}\right.$ VASc) score in this population. On POAF, no new recommendations have come forth. A natural question is why there is such disparity between advancements in the monitoring and treatment after surgical treatment of AF, but not of AF after surgical treatment of other cardiac lesions.

There are several potential etiologies of this discrepancy. First, POAF has historically been characterized as low in incidence, transient in nature, and benign in course. However, one should consider the context in which it is assessed. cations, data on its true prevalence may be limited with day period. This problem may be compounded by the limits thoracic surgery representative, has a few brief statements Because POAF falls in the bucket of postoperative complireportable postoperative metrics typically limited to a 30-

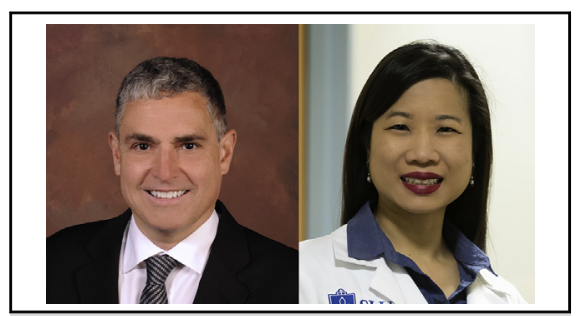

Richard Lee, MD, MBA, and Dawn S. Hui, MD

\section{Central Message}

Historically, POAF has been considered transient and relatively benign. Growing evidence suggests otherwise-particularly in the long term. Opportunities to improve the evidence base and treatment exist.

The Invited Expert Opinion provides a perspective on this topic based on the following paper: $\mathrm{J}$ of the American College of Cardiology, Volume 72, Issue 2, 2018, pp. 141-153. https:// doi.org/10.1016/j.jacc.2019.01.011. of detection. With increasing scrutiny of hospital stay as quality metric, shorter postoperative stays mean shorter monitoring periods and the possibility of underestimating POAF. One cannot see that for which one does not look. There is also a perception that in-hospital-detected POAF that converts to sinus rhythm is transient in nature. A few studies using contemporary monitoring modalities during the postdischarge period suggest that this perception might benefit from re-examination. A small study by Funk and colleagues, ${ }^{4}$ utilizing ambulatory symptom-linked event recorders plus daily transmitted electrocardiograms, found the in-hospital rate of AF to be $28 \%$ but the overall postoperative rate to be $42 \%$. After hospital discharge, $14 \%$ of patient had AF episodes, with the first episode occurring after postoperative day 5 in $>10 \%$ of patients. Another study using continuous ambulatory monitoring for 80 hours postoperatively found sustained (ie, lasting $>10$ minutes) POAF in $40 \%$ of postcoronary artery bypass grafting (CABG) patients. ${ }^{5}$ These hypothesis-generating findings have not translated into more extensive study nor use of longerterm monitoring in contemporary studies.

The idea that POAF is benign in course is reflected in the following sentence from a 2003 study: "Although postoperative AF usually does not result in long-term sequelae, it often increases length and cost of hospital stay due to hemodynamic compromise or thromboembolic 
complications." ${ }^{6}$ Recent data challenge the first part of this statement. New-onset POAF was a significant predictor not only of long-term AF, with a 5-fold higher incidence, but also of mortality at 3.5 years' follow-up in a propensity score analysis of isolated CABG patients. ${ }^{7}$ Post-hoc analysis of the Evaluation of the Xience versus Coronary Artery Bypass Surgery for Effectiveness of Left Main Revascularization (EXCEL) trial $^{8}$ found that new-onset POAF incurred a 4-fold risk of stroke (adjusted hazard ratio [aHR], 4.19; 95\% confidence interval [CI], 1.74-10.11). New-onset POAF was also associated with worse mortality at 30-days (odds ratio [OR], 5.0; 95\% CI, 14-18) and 1-year (aHR, 2.2; 95\% CI, 1.2-3.9) in an international multicenter study of 28 programs, and with death at 3 years in the EXCEL trial (aHR, 3.02; 95\% CI, 1.6-5.70).

Even with limited monitoring characterizing recent studies, POAF incidence seems to be increasing. After isolated $\mathrm{CABG}$, in-hospital AF was $28 \%$ in the STS multicenter Contemporary Analysis of Perioperative Cardiovascular Surgical Care Registry. ${ }^{10}$ The overall rate in a randomized trial was 30\% and nearly 50\% in those undergoing combined CABG/valve procedures. ${ }^{11}$ That these rates are several-fold higher than prior studies may reflect changes in the complexity of the operative procedures and patient comorbidities, ${ }^{12-14}$ including obesity, which confers a substantially greater POAF burden. ${ }^{15}$ Thus, the problem of POAF is one the cardiothoracic surgical community should reconsider, particularly in light of its association with long-term stroke and mortality.

\section{Future Directions: Opportunities}

Opportunities exist to begin addressing these many knowledge gaps in POAF by using tools already in use for the detection and management of AF. First, accurate data regarding the true incidence will be necessary to define the scope of the problem. This brings its own set of questions: What is the period of risk, and does it differ between those who experience early versus late POAF? Answering this question may require continuous ambulatory monitoring. Whether the costs of such devices will be covered is 1 issue, and the optimal duration of monitoring and patient compliance are 2 others. Edgerton and colleagues ${ }^{16}$ suggested that 7-days' monitoring after ablation of AF was ideal, but the optimal monitoring period after cardiac surgery without ablation has not been defined. Evolving developments in wearable technology ${ }^{17,18}$ may represent an opportunity for more convenient ambulatory monitoring but need further validation of their accuracy. Patients with existing cardiac devices represent an opportunity to study the incidence of POAF by routinely interrogating such devices postoperatively. However, such patients will certainly represent a selection bias.
The other 3 opportunities are prevention, risk stratification, and treatment. In the current guidelines, the only Class I recommendation for prevention of POAF is preoperative beta-blocker therapy. An analysis of the data for this recommendation suggests newer analysis may be needed. The primary citation was a 2004 Cochrane review ${ }^{19}$ of 28 randomized controlled trials on beta-blocker use, and there has since been a 2013 updated review. ${ }^{20}$ In the reviews, the outcome of interest was not AF alone but rather a combination of AF and supraventricular tachycardia. Half of the studies used propranolol, and most remarkably, $82 \%$ began the beta-blocker treatment postoperatively. Further, both reviews found significant heterogeneity across studies ( $I^{2}=64$ and 55, respectively). This is a quality metric that continues to be debated. A survey by the Society of Cardiovascular Anesthesiology (SCA) and European Association of Cardiothoracic Anaesthetists (EACTA) ${ }^{21}$ found that $36 \%$ followed this guideline "Sometimes" and $43 \%$ "Nearly always." Reported barriers to use were "Risk outweighs benefit" in $>50 \%$ of EACTA respondents and about one third of SCA respondents; "Bradycardia risk" and "Do not believe it has a benefit" were the next highest reasons. These concerns about safety and efficacy have been raised in the recent literature. A meta-analysis of isolated $\mathrm{CABG}$ studies found that preoperative beta-blocker use was associated with a significant increase in the incidence of POAF (OR, 1.08; 94\% CI, 1.06-1.10; $P<.001),{ }^{22}$ whereas a statewide database using propensity matched STS data of patients undergoing aortic valve replacement found preoperative beta-blocker associated with significantly increased POAF, as well as other morbidities of cardiac arrest, renal failure requiring dialysis, and postoperative transfusion. ${ }^{23}$

Amiodarone is a Class IIA recommendation for prophylaxis, but there was even greater concern about the riskbenefit ratio in the SCA/EACTA survey. The 2013 Cochrane review of 33 studies similarly found significant heterogeneity $\left(I^{2}=63\right)$ and that half of studies began administration postoperatively. ${ }^{20}$ Other measures for primary prevention included magnesium, statins, and colchicine, among many others. The uncertainty regarding efficacy of prophylaxis is reflected in the wide variation in implementation of POAF protocols. ${ }^{24,25}$ Until cardiac surgeons and anesthesiologists have the evidence to support confidence in the safety and efficacy of these adjunctive therapies, adoption will, and perhaps should, remain low.

Risk stratification may aid surgeons in choosing patients in whom the benefit of prophylactic measures might outweigh the risks. As previously discussed, the 2019 focused update deemed there to be insufficient evidence for utilization of $\mathrm{CHA}_{2} \mathrm{DS}_{2}$-VASc score in patients with $\mathrm{AF}$ and remote bioprosthetic valve implantation. A small study $(\mathrm{N}=277)$ of isolated CABG, valve, or CABG/valve 
patients found that new-onset POAF was independently predicted by $\mathrm{CHADS}_{2}(\mathrm{OR}, 1.54)$ and $\mathrm{CHA}_{2} \mathrm{DS}_{2}$-VASc (OR, 1.63) scores; Kaplan-Meier analysis showed a cutoff of 2 for both scoring systems. ${ }^{26}$ This finding was replicated in a study of 518 patients undergoing valvular surgery, with an incremental increase in POAF with as scores increased (area under the curve, 0.821 for $\mathrm{CHADS}_{2}$ and 0.765 for $\mathrm{CHA}_{2} \mathrm{DS}_{2}$-VASc). ${ }^{27}$ Notably, AF was defined by hospitalization, telemetry, or echocardiogram within 30 days, not continuous monitoring. Nevertheless, POAF rates were $30 \%$ in the first study and $45 \%$ in the latter, which found no difference in POAF incidence by valve operation type (ie, aortic vs mitral vs tricuspid). Other studies have concluded that current scoring systems are moderate at best and that better predictive models are needed. ${ }^{28,29}$

Scoring systems also do not correlate with prescribing practices. In the Contemporary Analysis of Perioperative Cardiovascular Surgical Care registry, there was a generally high prevalence of $\mathrm{CHADS}_{2}$ score $\geq 2$, which was significantly greater in those with POAF $(81 \%$ vs $75 \%$; $P=.001) .{ }^{10}$ Only $39 \%$ of those with POAF were prescribed warfarin at discharge, although warfarin data were missing in $43 \%$ of the cohort. In the EXCEL trial, oral anticoagulation was prescribed in only $10.1 \%$ of patients who developed POAF, also consisting of warfarin exclusively. ${ }^{8}$ Perhaps it was believed that, in the $85.8 \%$ of patients who had resolved AF by the time of discharge, recurrence would be low. It is also quite possible that lack of long-term monitoring and anticoagulation could explain the higher long-term stroke rates in POAF patients, rather than simply risk factors. Whether novel oral anticoagulants (NOACs), with standard dosing and absence of monitoring needs, will lead to greater prescribing practices and compliance remains to be seen. The eventual approval of reversal agents may also lead to greater comfort with prescribing NOACs. However, there are numerous reasons for continued caution. These include the higher risk of major bleeding with only 2 doses of dabigatran compared with warfarin in patients aged $\geq 75$ years, ${ }^{30}$ increased major pericardial bleeding with NOACs versus warfarin in the Randomized, Phase II Study to Evaluate the Safety and Pharmacokinetics of Oral Dabigatran Etexilate in Patients after Heart Valve Replacement trial, ${ }^{31}$ and limitations in patients with renal dysfunction such as contraindicated or altered dosing and generally higher bleeding risk.

\section{Future Directions: The Challenges}

The current thinking on POAF is demonstrated by what is among the few randomized, controlled trials of patients with this condition, ${ }^{11}$ in which the primary outcome was the total number of hospital days within 60 days after randomization to a rate versus rhythm control strategy. This end point may have allowed the investigators to accrue a sufficient sample with implications for shortterm management. In the context of the clinical outcomes we have just discussed, it may be time for studies to take a different approach. However, several challenges exist. A hurdle to defining incidence is the burden of postdischarge monitoring. For detecting AF in general, remote monitoring has a $95 \%$ sensitivity, but the question of cost and optimal monitoring duration remain. Costs associated with remote monitoring include not only the device itself, but also administrative resources such as trained personnel for rhythm interpretation, generation and communication of reports, and data entry into the medical records. However, as bundled payments move toward a longer 90-day global period, this cost may be offset by the benefit of earlier identifying and managing POAF before it triggers symptom-related readmissions or thromboembolic events. Taking an even longer-term view, there are data suggesting that outpatient monitoring is cost-effective for patients, providers, and health care systems. ${ }^{32}$ The second challenge is to improve the level of evidence. Even if studies with longer continuous monitoring demonstrate a higher incidence of short- to midterm POAF, there is clearly minimal effect; short-term stroke rates appear to be low as demonstrated by current identification and management strategies. Therefore, it may not be feasible to adequately design clinical trials that will meaningfully change current clinical practice.

We propose a reconceptualization of POAF. Contemporary data demonstrate that new-onset POAF is a marker for long-term risk of late AF, stroke, and mortality. Regardless of whether this relationship is causative or merely associative, it represents a potential to improve patient care. The many opportunities we have described may require collaboration with cardiology colleagues to generate sufficient Level A or B evidence to support surgical guidelines. In the era of the heart team approach to clinical care, such collaboration is not beyond plausibility.

\section{CONCLUSIONS}

The wide variation in practices for patients with newonset POAF after cardiac surgery is likely due to paucity of evidence. Historically, POAF has been believed to be due to acute inflammation and thus transient and benign. A growing body of evidence suggests otherwise. At the same time, an analysis of the evidence supporting the sparse guidelines reveals opportunities for improvement.

\section{Conflict of Interest Statement}

Authors have nothing to disclose with regard to commercial support. 


\section{References}

1. Ad N, Damiano RJ, Badhwar V, Calkins H, La Meir M, Nitta T, et al. Expert consensus guidelines: examining surgical ablation for atrial fibrillation. $J$ Thorac Cardiovasc Surg. 2017;153:1330-54.

2. January CT, Wann LS, Alpert JS, Calkins H, Cigarroa JE, Cleveland JC Jr, et al. 2014 AHA/ACC/HRS guideline for the management of patients with atrial fibrillation: a report of the American College of Cardiology/American Heart Association task force on practice guidelines and the Heart Rhythm Society. J Am Coll Cardiol. 2014;64:e1-76.

3. January CT, Wann LS, Calkins H, Chen LY, Cigarroa JE, Cleveland JC Jr, et al. 2019 AHA/ACC/HRS focused update of the 2014 AHA/ACC/HRS guideline for the management of patients with atrial fibrillation. J Am Coll Cardiol. 2019; https://doi.org/10.1016/j.jacc.2019.01.011.

4. Funk M, Richards SB, Desjardins J, Bebon C, Wilcox H. Incidence, timing, symptoms, and risk factors for atrial fibrillation after cardiac surgery. Am J Crit Care. 2003;12:424-33.

5. Kalman JM, Munawar M, Howes LG, Louis WJ, Buxton BF, Gutteridge G, et al. Atrial fibrillation after coronary bypass grafting is associated with sympathetic activation. Ann Thorac Surg. 1995;60:1709-15.

6. Tagdi T, Nalbantgil S, Ayik F, Apaydin A, Islamoglu F, Posacioglu H, et al. Amiodarone reduces the incidence of atrial fibrillation after coronary artery bypass grafting. J Thorac Cardiovasc Surg. 2003;125:1420-5.

7. Lee SH, Kang DR, Uhm JS, Shim J, Sung J-H, Kim J-Y, et al. New-onset atrial fibrillation predicts long-term newly developed atrial fibrillation after coronary artery bypass graft. Am Heart J. 2014;167:593-600.

8. Kosmidou I, Chen S, Kappetein AP, Serruys PW, Gersh BJ, Puskas JD, et al. New-onset atrial fibrillation after PCI or CABG for left main disease: the EXCEL trial. J Am Coll Cardiol. 2018;71:739-48.

9. Akintoye E, Sellke F, Marchioli R, Tavazzi L, Mazaffarian D. Factors associated with postoperative atrial fibrillation and other adverse events after cardiac surgery. J Thorac Cardiovasc Surg. 2018;155:242-51.

10. Steinberg BA, Zhao Y, He X, Hernandez AF, Fullerton DA, Thomas KL, et al. Management of postoperative atrial fibrillation and subsequent outcomes in contemporary patients undergoing cardiac surgery: insights from the Society of Thoracic Surgeons CAPS-Care atrial fibrillation registry. Clin Cardiol. 2014;37:7-13.

11. Gillinov AM, Bagiella E, Moskowitz AJ, Raiten JM, Groh MA, Bowdish ME, et al. Rate control versus rhythm control for atrial fibrillation after cardiac surgery. N Engl J Med. 2016;374:1911-21.

12. El-Chami MK, Kilgo P, Thourani V, Lattouf OM, Delurgio DB, Guyton RA, et al, New-onset atrial fibrillation predicts long-term mortality after coronary artery bypass graft. J Am Coll Cardiol. 2010;55:1370-6.

13. El Bardissi AW, Aranki SF, Sheng S, O'Brien SM, Greenberg CC, Gammie JS. Trends in isolated coronary artery bypass grafting: an analysis of the Society of Thoracic Surgeons adult cardiac surgery database. J Thorac Cardiovasc Surg. 2012; 143:273-81

14. Lee R, Li S, Ranking JS, O'Brien SM, Gammie JS, Peterson ED, et al. Fifteenyear outcome trends for valve surgery in North America. Ann Thorac Surg. 2011; 91:677-84.

15. Serban C, Arinze JT, Starreveld R, Lanters EAH, Yaksh A, Kik C, et al. The impact of obesity on early postoperative atrial fibrillation burden. J Thorac Cardiovasc Surg. 2019; https://doi.org/10.1016/j.jtcvs.2019.03.073.

16. Edgerton JR, Mahoney C, Mack MJ, Roper K, Herbert MA. Long-term monitoring after surgical ablation for atrial fibrillation: how much is enough? J Thorac Cardiovasc Surg. 2011;142:162-5.
17. Nemati S, Ghassmi MM, Ambai V, Isakadze N, Levantsevych O, Shah A, et al Monitoring and detecting atrial fibrillation using wearable technology. Conf Proc IEEE Eng Med Biol Soc. 2016;2016:3394-7.

18. Harju J, Tarniceriu A, Parak J, Vehkaoja A, Yli-Hankala A, Korhonen I. Monitoring of heart rate and inter-beat intervals with wrist plethysmography in patients with atrial fibrillation. Physiol Meas. 2018:39:065007.

19. Crystal E, Connolly SJ, Sleik K, Ginger TJ, Yusuf S. Interventions on prevention of postoperative atrial fibrillation in patients undergoing heart surgery: a metaanalysis. Cochrane Database Syst Rev. 2004;4:CD003611.

20. Arsenault KA, Yusuf AM, Crystal E, Healey JS, Morillo CA, Nair GM, et al. Interventions for preventing post-operative atrial fibrillation in patients undergoing heart surgery (review). Cochrane Database Syst Rev. 2013;1: CD003611.

21. O’Brien B, Burrage PS, Ngai JY, Prutkin JM, Huang CC, Xu X, et al. Society of Cardiovascular Anesthesiologists/European Association of Cardiothoracic Anaesthetists practice advisory for the management of perioperative atrial fibrillation in patients undergoing cardiac surgery. J Cardiothorac Vasc Anesth. 2019; $33: 12-26$

22. Wang L, Sang H, Hou X. Short-term effects of preoperative beta-blocker use for isolated coronary artery bypass grafting: a systematic review and meta-analysis. $J$ Thorac Cardiovasc Surg. 2018;155:620-9.e1.

23. Schuber SA, Hawkins RB, Mehaffey JH, Fonner CE, Rich JB, Speir AM. Preoperative $\beta$-blocker use correlates with worse outcomes in patients undergoing aortic valve replacement. J Thorac Cardiovasc Surg. February 13, 2019; https://doi.org/10.1016/j.jtcvs.2018.12.108.

24. Maaroos M, Tuomainen R, Price J, Rubens FD, Jidus RL, Halonen J, et al. Preventive strategies for atrial fibrillation after cardiac surgery in Nordic countries. Scand J Surg. 2013;102:178-81.

25. Alawami M, Chatfield A, Ghashi R, Walker L. Atrial fibrillation after cardiac surgery: prevention and management: the Australasian experience. J Saudi Heart Assoc. 2018;30:40-6.

26. Chua SK, Shyu KG, Lu MJ, Lien LM, Lin CH, Chao HH, et al. Clinical utility of CHADS2 and CHA2DS2-VASc scoring systems for predicting postoperative atrial fibrillation after cardiac surgery. J Thorac Cardiovasc Surg. 2013;146: 919-26.e1.

27. Yin L, Ling X, Zhang Y, Shen H, Min J, Xi W, et al. CHADS2 and CHA2DS2 VASc scoring systems for predicting atrial fibrillation following cardiac valve surgery. PLoS One. 2015;10:e123858.

28. Pollock BD, Filardo G, da Graca B, Phan TK, Ailawadi G, Thourani V, et al. Predicting new-onset post-coronary artery bypass graft atrial fibrillation with existing risk scores. Ann Thorac Surg. 2018;105:115-21.

29. Cameron MJ, Tran DTT, Abboud J, Newton EK, Rashidian H, Dupuis JY Prospective external validation of three preoperative risk scores for prediction of new onset atrial fibrillation after cardiac surgery. Anesth Analg 2018:126:33-8.

30. Eikelboom JW, Wallentin L, Connolly SJ, Ezekowitz M, Healey JS, Oldgren J, et al. Risk of bleeding with 2 doses of dabigatran compared with warfarin in older and younger patients with atrial fibrillation: an analysis of the randomized evaluation of long-term anticoagulant therapy (RE-LY) trial. Circulation. 2011;123: 2363-72.

31. Eikelboom JW, Connolly SJ, Brueckmann M, Granger CB, Kappetein AP, Mack MJ, et al. Dabigatran versus warfarin in patients with mechanical hear valves. $N$ Engl J Med. 2013;369:1206-14.

32. Burri H, Heidbüchel H, Jung W, Brugada P. Remote monitoring: a cost or an in vestment? Europace. 2011;13:ii44-8. 